\section{Controversies in Therapeutics}

\section{When to start anticonvulsant treatment in childhood epilepsy: the case for early treatment}

\author{
C M Verity
}

The effect of a convulsion on the nerve centres is such as to render the occurrence of another more easy, to intensify the predisposition that already exists.'

Is it really true that one convulsion leads to another? Every seizure may potentially cause brain damage and early treatment would stop such damage by preventing further seizures. The evidence that seizures can cause brain damage is summarised below.

\section{Clinical evidence}

There is little doubt that seizures are harmful if they are sufficiently prolonged. Aicardi and Chevrie found a poor outlook when they studied 239 children with status epilepticus: $27(11 \%)$ died and at least $136(57 \%)$ had mental or neurological disability. ${ }^{2}$ When children die after prolonged convulsions characteristic neuronal damage is found in several areas of the brain (figures). ${ }^{3}$

Falconer reported hippocampal damage in more than half of the temporal lobes removed from patients with intractable temporal lobe epilepsy. ${ }^{4}$ The term "mesial temporal sclerosis" was used to describe the lesion, which often included the amygdala and the uncus as well as the hippocampus. Falconer suggested that severe febrile convulsions were an important cause of mesial temporal sclerosis because a significantly greater number of patients with this lesion gave a history of prolonged covulsions in childhood.

\section{Experimental evidence}

Meldrum induced prolonged seizures (more than 3.5 hours) in baboons and showed that damage was localised to the cerebral cortex, the thalamus, and the hippocampus. ${ }^{3}$ The animals were paralysed and ventilated so that the secondary effects of prolonged seizures (hyperpyrexia, hypoxia, hypotension, and hypoglycaemia) were prevented. The experiments therefore suggested that the epileptic discharges themselves were responsible for the damage, possibly by causing Cambridge CB2 2QQ

C M Verity, MRCP, consultant paediatric neurologist

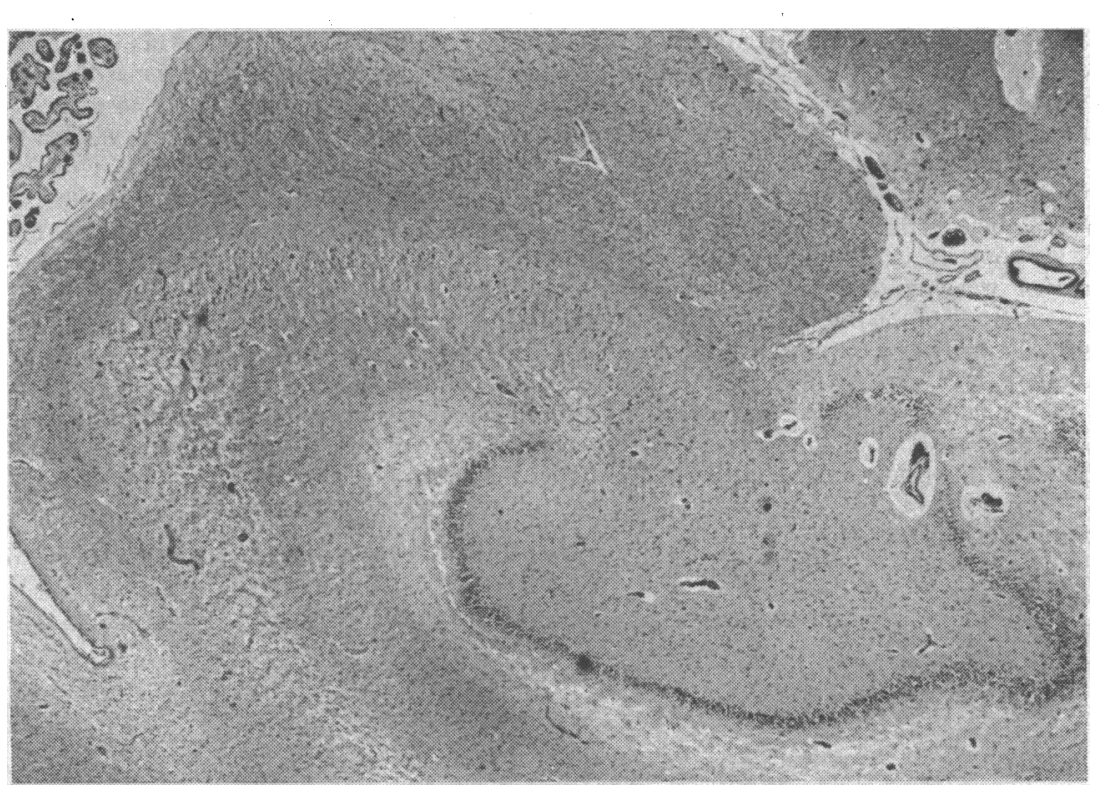

Photomicrograph of coronal section through hippocampus showing neuronal loss in Sommer section. Characteristic neuronal damage is also found in cerebral cortex and Purkinje cells of cerebellum. (Haematoxylin and eosin)

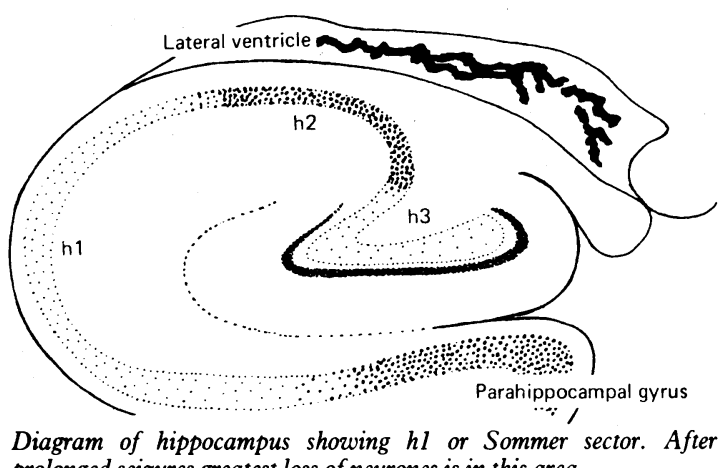
prolonged seizures greatest loss of neurones is in this area

the release of "excitotoxins"-amino acids that harm postsynaptic cells (B S Meldrum, Ronnie MacKeith lecture, annual meeting of the British Paediatric Neurology Association, Nottingham, 1987).

When repeated subthreshold electrical stimuli are applied to discrete areas of grey matter they kindle or facilitate seizure discharges and then lead to generalised convulsions. The phenomenon of kindling was first observed during experiments in rats, ${ }^{5}$ but it may be important in the pathogenesis of epilepsy in humans. A separate mirror focus may develop in the corresponding part of the opposite hemisphere. Seizure discharges may spread by this process to cause increasingly severe epilepsy.

\section{When to start treatment with anticonvulsant drugs}

Sometimes anticonvulsant drugs are clearly indicated because of the frequency or severity of the attacks. The decision is less easy when a child develops febrile convulsions or presents with a first afebrile seizure.

\section{FEBRILE SEIZURES}

Studies of children seen in hospitals or clinics have found a disturbingly high incidence of epilepsy and mental retardation after febrile seizures. ${ }^{6}$ Population based studies have enrolled a less selected group of children $^{7-10}$ and give a more optimistic view of the prognosis. They have, however, identified a group of children who are at particular risk of recurrent febrile seizures or of later epilepsy, or both.

A National Institutes of Health consensus statement recognised that certain children with seizures associated with fever were particularly at risk and suggested that anticonvulsant prophylaxis be considered when (a) neurological development is abnormal; $(b)$ a febrile seizure is longer than 15 minutes, focal, or followed by transient or persistent neurological abnormalities; $(c)$ a parent or sibling has a history of non-febrile seizures of genetic origin; $(d)$ a patient has multiple seizures; and (e) seizures occur in an infant under the age of 12 months. ${ }^{11}$

The consensus provides a sound basis for deciding when to start anticonvulsant drugs in children with febrile seizures. ${ }^{12}$ Gordon $^{13}$ and Wallace ${ }^{14}$ broadly agree with the recommendations and their reviews should be consulted for further details.

\section{AFEBRILE SEIZURES}

Recurrent seizures-Reynolds and his colleagues studied newly referred adults with previously un-

continued on page 1530 
Controversies in

\section{Therapeutics}

longer the interval between the first seizure and surgery, the less favourable the clinical result. ${ }^{6}$

Relapse rate after withdrawal of anticonvulsants related to total number of seizures before control by anticonvulsant treatment

\begin{tabular}{lcccc}
\hline & $\begin{array}{l}\text { Total No of seizures before } \\
\text { control by anticonvulsants }\end{array}$ \\
\cline { 2 - 4 } & $3-5$ & $6-12$ & $>12$ \\
\hline Relapse after withdrawal of anticonvulsants (\%) & 27 & 32 & 28
\end{tabular}

Kindling of the hippocampus and amygdala by the irritative temporal lobe focus has been a suggested explanation for this observation. There is, however, an equally tenable but more mundane interpretation; cases of short duration temporal lobe epilepsy have a better prognosis than those of long duration whether or not they come to operation.

\section{Treatment considerations}

Long term treatment with anticonvulsant drugs carries well known risks of idiosyncratic and dose related side effects, some of which may be life threatening such as Stevens-Johnson syndrome, blood dyscrasias, and liver failure. Little is known of the permanent effects of these drugs on the developing nervous system, but many are recognised as being able to produce subtle cognitive and behavioural changes in some children even when blood concentrations are maintained within the so called therapeutic range. No completely safe anticonvulsant drug is known or is likely to be developed. Children should not be given long term anticonvulsant treatment unless the benefits clearly outweigh the risks.
Parents of children who have had febrile convulsions should be instructed in managing fever and giving rectal diazepam if required. The overall prognosis for febrile convulsions is excellent. ${ }^{7}$ Only $2 \%$ develop epilepsy with non-febrile seizures, although recurrence with one or more febrile convulsions occurs in $35 \%$. Even in children with prolonged, recurrent, or other complicated febrile convulsions the risk of subsequent epilepsy is only $4 \%$.

There is no indication for starting long term anticonvulsant treatment after a single afebrile convulsive seizure. Hauser $e t$ al found that the cumulative risk of recurrence was only $18 \%$ at one year, $21 \%$ at two years, and $27 \%$ at three years. ${ }^{8}$ If the seizure is prolonged, however, the parents should be taught how to give rectal diazepam. In the case of recurrent afebrile seizures many factors come into the decision, including the type of epileptic seizure and parental attitudes. In general, however, long term anticonvulsant treatment should be delayed until it becomes clear that there are no signs of spontaneous resolution and that the continuing seizures are adversely affecting the child's life. In so doing some children will avoid ever having to start long term treatment.

1 Von Rosenstein. Diseases of children and their remedies. British ed, 1766. Quoted by Brett EM. Paediatric neurology. Edinburgh: Churchill Livingstone, 1983:275.

2 Rodin EA. The prognosis of patients with epilepsy. Springfield, Illinois: Charles C Thomas, 1968.

3 Annegers JF, Hauser WA, Elverback LR. Remission of seizure and relapse in patients with epilepsy. Epilepsia 1979;20:729-37.

4 Glaser GH. Kindling. Dev Med Child Neurol 1983:25:376-80.

5 Thurston JH, Thurston DL, Hixon BB, Keller AJ. Prognosis of childhood epilepsy: additional follow-up of 148 childten 15 to 23 years after withdrawal epilepsy: additional follow-up of 148 childten 15 to 23 yea

$6 \mathrm{Glaser} \mathrm{GH}$. Treatment of intractable temporal lobe-limbic epilepsy (complex partial seizures) by temporal lobectomy. Ann Neurol 1980;8:455-9.

partial seizures, by temporal lobectomy. Ann Neurol $1980 ; 8: 455-9$.
Nelson KB, Ellenberg JH. Predictors of epilepsy in children who have Nelson KB, Ellenberg JH. Predictors of epilepsy in children
experienced febrile convulsions. N Engl f Med 1976;295:1029-33.

8 Hauser WA, Anderson VE, Loewenson RB, McRoberts SM. Seizure recurrence after a first unprovoked seizure. $N$ Engl F Med 1982;307:522-8

\section{M Verity \\ continued from page 1528}

treated seizures. ${ }^{15}$ Their results are relevant to a discussion about treating children. They obtained evidence that early suppression of seizures improved the subsequent prognosis: the longer the seizures continued after the start of treatment the less likely they were to go into remission; a high pretreatment frequency of tonic-clonic seizures indicated a worse prognosis; and in patients who had two or more tonic-clonic attacks before the start of treatment the interval between attacks tended to become shorter. Thus an escalating process seems to be found and should be arrested as soon as possible. Reynolds found that rates of remission were lower in patients with neuropsychiatric handicap, cerebral pathology, or partial (rather than tonic-clonic) seizures. The presence of one or more of these factors might be an indication for earlier treatment.

Single seizures-Should people be treated after a first seizure? Several reviews have pointed out that the question is difficult to answer..$^{15-17}$ One of the reasons is that there is disagreement about the prognosis: $27 \%$ of patients had a recurrence after three years in one study, $80 \%$ in another. ${ }^{15}$ There is general agreement on one point: no adequate investigation of the problem has been carried out.

\section{Conclusion}

Severe seizures can undoubtedly cause neurological damage. The difficulty is in knowing how actively to treat short or infrequent attacks. Evidence shows that early treatment may arrest an escalating process in patients with seizures and that some high risk groups are at particular risk of recurrence. A policy of early treatment might save more patients from chronic epilepsy.

I thank Dr Janice Anderson, for supplying the diagram and the photomicrograph.

: Gowers WR. Epilepsy and other chronic convulsive diseases. London: Churchill Livingstone, 1881.

2 Aicardi J, Chevrie JJ. Convulsive status epilepticus in infants and children. A study of 239 cases. Epilepsia 1970;11:187-97.

3 Meldrum BS. Secondary pathology of febrile and experimental convulsions. In: Brazier MAB, Coceani $\mathrm{F}$, eds. Brain dysfunction in infantile febrile In: Brazier MAB, Coceani F, eds. Brain
convulsions. New York: Raven, 1976:213-22.

4 Falconer MA. Surgical treatment of sequelae of severe febrile convulsions. In: Brazier MAB, Coceani F, eds. Brain dysfunction in infantile febrile convulsions. New York: Raven, 1976:307-26.

5 Goddard GV. Development of epileptic seizures through brain stimulation at low intensity. Nature 1967;214:1020-1.

6 Aicardi J, Chevrie JJ. Febrile convulsions: neurological sequelae and mental retardation. In: Brazier MAB, Coceani F, eds. Brain dysfunction in infantile febrile convulsions. New York: Raven, 1976:247-57.

7 Nelson KB, Ellenberg JH. Predictors of epilepsy in children who have experienced febrile seizures. $N$ Engl f Med 1976;295:1029-33.

8 Ellenberg JH, Nelson KB. Febrile seizures and later intellectual performance. Arch Neurol 1978;35:17-21.

9 Verity CM, Butler NR, Golding J. Febrile convulsions in a national cohort followed up from birth. I. Prevalence and recurrence in the first five years of life. Br Med J 1985;290:1307-10.

10 Annegers JF, Hauser WA, Shirts SB, Kurland LT. Factors prognostic of unprovoked seizures after febrile convulsions. $N$ Engl $f$ Med 1987;316: unprov

11 National Institutes of Health. Febrile seizures: long-term management of children with fever-associated seizures. Summary of an NIH consensus statement. Br Med f 1980;281:277-9.

12 Anonymous. The management of febrile convulsions. Drug Ther Bull 1987;25 9-11.

13 Gordon N. Epilepsy-to treat or not to treat. Pediatric Rev Commun 1987;1:163-80.

14 Wallace SJ. The child with febrile seizures. London: John Wright, 1988.

15 Reynolds EH. The initiation of anticonvulsant drug therapy: implications for prognosis. In: Pedley TA, Meldrum BS, eds. Recent advances in epilepsy. No 2. London: Churchill Livingstone, 1985:101-9.

16 Hauser WA. Should people be treated after a first seizure? Arch Neurol 1986;43:1287-8.

17 Shorvon S. When should anticonvulsant treatment be started? In: Ross E, Chadwick D, Crawford R, eds. Epilepsy in young people. Chichester: Wiley, 1987:53-63. 